\title{
Keeper: A Synchronous Online Conversation Environment Informed by In-Person Facilitation Practices
}

\author{
Margaret A. Hughes \\ mhughes4@media.mit.edu \\ Massachusetts Institute of Technology \\ Cambridge, Massachusetts
}

\author{
Deb Roy \\ dkroy@media.mit.edu \\ Massachusetts Institute of Technology \\ Cambridge, Massachusetts
}

\begin{abstract}
Facilitation, or the craft and use of specific tools, methods, and practices to influence the way groups gather and converse to reach a goal, requires the nuanced craft of a facilitator to guide complex conversations. Online gathering spaces are often designed with neither the facilitator's knowledge nor the range of tools their methods require, making online facilitation difficult. In this paper, we describe the design and evaluation of Keeper - an online video call extension environment - informed by the widespread, foundational facilitation method of Circle practice. We define three initial facilitator-driven goals of the platform: 1) enable tone setting, 2) ease the practice and smoothness of online conversation, and 3) improve social presence. After a qualitative study with 72 participants, semi-structured interviews with facilitators, and an RCT with 100 participants, we observe improved tone setting and ease of conversation and suggest several ways to further pursue improved online conversation.
\end{abstract}

\section{KEYWORDS}

facilitation; interface design; Circle; $\mathrm{HCI}$

\section{ACM Reference Format:}

Margaret A. Hughes and Deb Roy. 2021. Keeper: A Synchronous Online Conversation Environment Informed by In-Person Facilitation Practices. In CHI Conference on Human Factors in Computing Systems (CHI '21), May 8-13, 2021, Yokohama, Japan. ACM, New York, NY, USA, 14 pages. https: //doi.org/10.1145/3411764.3445316

\section{INTRODUCTION}

Conversation facilitation, or the specific tools, methods, and practices to influence the way groups gather and converse to reach a goal, is an "ancient social technology" that requires the nuanced craft of a facilitator to guide complex conversations. While facilitation dates back to early human-history, facilitation and intentional, focused group gatherings have become recognized as essential from workplace meetings, to community building with friends, to overcoming great harms such as sexual assault $[6,64]$. Foundational to most conversation facilitation styles, Circle practice is ancient and highly impactful in the modern era. Designed by Indigenous groups of North America, Circle practice enabled storytelling, celebration,

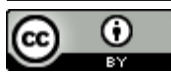

This work is licensed under a Creative Commons Attribution International 4.0 License.

Yokohama '21, May 08-13, 2021, Yokohama, Japan

(c) 2021 Copyright held by the owner/author(s).

ACM ISBN 978-1-4503-8096-6/21/05.

https://doi.org/10.1145/3411764.3445316 and decision making among other goals [7]. After appropriation into the Restorative Justice movement in the United States in the 1970s and the Truth and Reconciliation Commission post-apartheid in South Africa, the practitioners of Circle have expanded from Indigenous peoples to system involved or incarcerated people, government officials, social workers and teens in schools, and beyond [21]. Further, Circle less legibly influences most other facilitation practices that strive for understanding, community, storytelling, and healing such as Dialogue Across Divides, TheoryU, and consensus building [3, 49].

As more groups spread online in the modern era or are pushed online during the COVID-19 pandemic, facilitation methods are being adapted to an online context. However, online spaces such as Zoom and Google Hangouts are not designed with the unique needs and knowledge of facilitators in mind, and are not designed to hold the range of tools, methods, practices, and crafts they require.

In this paper, we describe the design exploration and evaluation of an online platform, Keeper, designed and informed by Circles practices to aid online facilitated conversations. In this paper, we define the goals of the platform informed by Circle practice and other facilitation styles like it: 1) enable a calm, welcoming tone 2) ease the practice and smoothness online conversations and 3) improve social presence online. After initial iterative explorations with 72 participants across 15 conversations, semi-structured interviews with 8 experienced facilitators of Circle or Circle-aligned facilitation methods, and a randomized controlled trial with 100 participants across 25 conversations, we observe patterns that suggest tone and ease of conversation are improved with the introduction of this tool, and that the tool could improve social presence online.

We contribute to the field of Human-Computer Interaction (HCI) and interface design by identifying a gap within computer-mediated communication $(\mathrm{CMC})$ and $\mathrm{HCI}$ platforms in that they are rarely designed with the knowledge of the in-person facilitation practice, Circle, though it has proven significantly impactful and influential globally. Further, we take one step towards shrinking that gap through the creation and evaluation of a platform with goals that align with wisdom from Circle-aligned facilitation practices. Through qualitative explorations, interviews with experts, and a randomized control trial, we show that Keeper and perhaps other platforms like it could ease and improve the experience of participants and facilitators online. Finally, in the midst of a pandemic and a national reckoning with police and criminal justice systems in the United States, platforms that promote intimacy and connection online when people cannot physically be together, and platforms that enable practice of alternative justice systems (such as Restorative Justice which uses Circle as a mechanism of restoration from harm) 
can contribute to the improvement and betterment of a rapidly evolving world.

\section{RELATED WORK}

\subsection{Circle Practice}

In Circle facilitation, Circle keepers (facilitators) invite participants to sit in a circle, set the tone of a space through smells, sounds and symbols, actively hold and facilitate the group, and use turn-taking to prompt participants to share thoughts. They invite participants to offer personal stories, and practice deep listening by withholding from interruptions, and to share values and create a set of agreements with the group. Decisions are generally made through consensus building, and Circles are often non-hierarchical. The facilitator prompts the group to answer questions, often inviting participants to talk about personal experience and stories. Often within Circle, facilitators use a talking piece to regulate turn taking and have a co-created, earth-connected center piece to set the tone of the space as special and sacred [28]. Such a model is used in Talking Circles to deepen relationships, Story Circles to share life experiences and promote intimacy in groups, Consensus Circles to make decisions and reach a non-hierarchical consensus, among other venues [32, 78]. The consistent use of Circles within groups as maintenance has shown to increase participants' sense of community, improve culture and achievement, and bolster the foundation of the community for children and adults [56, 73]. In practice, Circle has been used as a key component of de-carceration within the era of mass incarceration and the school-to-prison pipeline particularly targeting Black, Brown, and Indigenous people in the United States and Canada. Developed and used widely by Native American peoples, the practice is carried and spread through groups and individuals like Restorative Justice for Oakland Youth (RJOY), the Suffolk Center for Restorative Justice, Living Justice Press, and Unity Circles $[9,15,16,19]$. Further, it was a mechanism to help South Africa begin to heal after generations of oppression and violence post-apartheid, and has enabled healing for those who have experienced violent crimes such as sexual assault $[6,28,68,80]$.

Facilitators currently practice across distance through video calls, telephone calls, chat rooms, and blogs. Circle-esc practices used in support groups have translated their practices into online spaces [2]. Further, amidst the pandemic, schools have begun practicing Restorative Justice Circles online [15]. The Circle community has been sharing best practices for online facilitation widely, including guidance to turn video cameras on, use Zoom's breakout rooms, encourage turn taking without a talking piece, structure the conversation in advance, and so forth. Yet, rarely does guidance suggest to use other mediums besides traditional video call platforms, and we have yet to find research on the effectiveness and quality of these Circle-esc facilitation styles online $[3,4,8,18]$. In the following section, we outline existing designs that have the potential to support and where they fail to support virtual Circle.

\subsection{Virtual Facilitation Tools}

2.2.1 Productivity. While many platforms within $\mathrm{HCI}$ and ComputerSupported Cooperative Work (CSCW) sit at the intersection of facilitation and technology, most are currently designed for improved productivity, efficiency, brainstorming, and problem solving. Rarely are the goals to increase sense of understanding and connection found in Circle practice. Facilitation tools that are designed specifically for pro-social behavior explore important domains, such as movement, flexibility, tone, and live data visualization within CMC to augment conversations positively, but are exploratory and rarely incorporate or align with the goals of ancient practices like Circle [67]. Those that do focus on connection look at synchrony, and find positive results such as ease when intervening to promote synchrony, but do not explore intimacy or conversation [63]. Many commercial platforms, as well, have similar goals of increased productivity such as Mur [14] or Mir [12] [5, 11, 12, 14, 17]. Others that explore the experience of the user, including their speaking time, rate of turn taking, and tone like Meeting Mediator and Breakout still measure success in terms of task solving or efficiency rather than feelings of connection or intimacy, biasing the design away from Circle-esc practices [30, 52, 76].

2.2.2 Deliberative Facilitation. A great deal of work within the $\mathrm{HCI}, \mathrm{CSCW}$, and facilitation communities explore virtual facilitation as a means to support deliberative democracy [35, 40, 41]. Cavalier's PICOLA explores a round-table discussion style, with a platform that accommodates asynchronous discussion as well as live synchronous discourse [31]. User's can signal emotions, and join a queue, and are limited to "jumping" the queue a few times each discussion. The platform is oriented towards deliberation and incorporates signals such as frowns or thumbs down, and offers a space for learning and discussion around political issues. While the round table structure, turn taking, and moderation aligns with the needs of Circle, the added signals, lack of tone setting, and little emphasis on social presence or community connection limit the platform.

Others explore asynchronous mediated discourse, as well, with moderated text chat discussions [41]. For example, Epstein and Leshed [41] explore how moderators in asynchronous deliberative discussions can move messages around on a chat interface to improve discourse quality. Further, Nelimarkka et al. [59] explore novel interfaces in social media that decrease polarization and increase complexity within political discourse through diverse content recommendations [59]. Their focus is on de-polarization and not connection, but their emphasis on increased complexity and pro-social systems align with Keeper's goals. And while deliberative democracy is not the focus of this paper, the field has produced extensive exploratory work in facilitation and $\mathrm{HCI}$ that has influenced Keeper's design (such as turn-taking mechanisms, promoting pro-social behaviors, prioritizing complexity over reductive opinions), and is ripe for further exploration [58, 77].

2.2.3 Facilitated Personal Connection Platforms. Projects that are inspired by or mirror Circle practice include Circl.es [1], the Local Voices Network [10], and Intertwinkles [36]. Intertwinkles focuses on decision making mechanisms specifically, but unlike other platforms, focuses on non-hierarchical, distributed, consensus based models of decision making, aligning with the distributed, consensusbased, non-hierarchical model of Circle (though the platform and designer do not reference Circle, to our knowledge). The Local Voices Network and it's digital hearth use hardware tools as a way to aid facilitators as they hold discussions by introducing audio snippets from conversations across cities to promote empathy[42]. 
And while this tool aids the flow of conversations, supports a facilitator by playing stories from other conversations, and lightly sets the tone of a conversation (with a warm orange glow of the hearth and calming sounds), the device offers no support for conversations virtually. [1], on the other hand, is designed directly after Circle practice, organizing participants of a video call around Circle [1] It uses music as a mechanism for tone-setting, enables structured turn taking through a speaker-queue, and incorporates features such as a virtual "hug," where each user's video drifts to the person they are hugging, to promote intimacy, care, and social presence. However, even with such features to promote intimacy, the tool is designed with the frame of improving company productivity, and no research on this platform has been published exploring the influence of such an intervention to our knowledge.

\subsection{Circle Aligned Design and HCI}

The HCI and CSCW community and beyond has explored human representation, tone setting, and turn-taking rigorously and in depth, and many of these designs can support Circle online. In the following sections, we outline a wide array of such examples in research and design that informed the design choices in Keeper.

2.3.1 Social Presence. Exploring social presence further required understanding the affiances of various computer mediated communication mediums. Oh et al. [60] 2018 systematic review of social presence shows that audio-only communication offers high social presence online while some research finds video to improve social presence especially when given visual tasks such as puzzles. Other studies, however, find no significant increase of social presence from audio to audio-video calls during decision or interview processes (without visual tasks) [43, 53, 61, 79].

Yet, audio alone in conversation does not lead to as rich a conversation as in some instances of audio with avatar representations of users [51]. When comparing speaking with an "invisible" partner or a partner with an avatar, Kim et al. [51] finds the CMC system with avatars increases social presence compared to the "invisible" partner. Yet, the specific features of the avatar are important. For example, human-behavior signals such as nodding and gaze positively impact social presence [24, 25, 62]. However, realistic, humanoid avatars are less important for social presence than human behavior signals are, and can actually decrease social presence if the human behavior signals are less-rich than the realism of the avatars [26]. Further, researchers challenge traditional uses of space in virtual platforms to play with social presence, for example by making the environment have depth or representing participants as abstract shapes [20, 37, 46].

2.3.2 Tone Setting. The design explorations into influencing affect and tone are expansive, but for the sake of this paper, we are inspired by work from three domains specifically: affective computing, soma-design, and sacred architecture. Within affective computing, projects such as BrightBeat, a system that subtly influences a user's breathing rate through oscillating the brightness of their screen and the loudness of their audio to the beat of a goal breathing rate, has proven to increase feelings of calm, without decreasing focus [45]. Exercises or cues to slow breathing to an ideal rate have been found to promote relaxation for patients with hyper-tension, addiction, anxiety, and mental illness [27, 29, 57], and have been used as a mindfulness more broadly [23, 65, 72]. Further, somadesign explores a similar concept with physical objects to make a user mindful with similar human-body informed signals [48]. And while we do not explore bio-metric feedback or emotionally intelligent computation with Keeper, we learn from how systems such as BrightBeat pull from knowledge within psychology to influence a user's affect and set the tone of an experience.

Finally, because space is so essential within Circle practice, we explored theory within architecture and sacred spaces. Architects have long understood the design of a space can influences a user's experience within that space, and design to dictate that experience. To achieve sacred, intimate spaces, high-contrast and light choice, is one marker of a sacred space across many cultures [54, 70, 71]. Further, colors can influence the experience of a user and can have cultural and instinctual connotations with emotions [50].

2.3.3 Turn-Taking. Turn-taking is an extensive domain of study within conversation analysis, computer-mediated communication, and social presence theory [22, 39, 44, 69, 75]. For example, Suggs [75] explores raising hand features and other turn-taking mechanisms in online courses to ease class flow. Others like Earnshaw [39] explore turn-taking and repair, or how participants repair a mistake such as an interruption or misunderstanding online. And while more technologically complex interventions explore how to make turn-taking seamless (by augmenting gaze, for example [34]) others explore moderated turn-taking through queues, randomized turn order, and non-ordered systems such as hand-raising. Some explore breaking the queue, and other asynchronous platforms often have turn-taking embedded in the reply structure [31, 41]. Further, timed turn-taking has been explored, as well, but can be stressful and not inviting for participants in Circle [1, 31]. Because Circle has such a concrete turn taking system, we designed the turn taking of Keeper informed directly by the facilitation style, filling what seems to be a small gap in turn-taking research in HCI.

\section{SYSTEM DESIGN: KEEPER}

Seeing the gap in online personal connection-oriented facilitation practices, the first author conducted a 1.5 year ethnographic study of and became a trained practitioner in Circle and similar facilitation practices in-person and online [47]. From this study, we identified a series of design principles. With those principles, we designed, iterated, and prototyped Keeper informed by the in-person facilitation practice of Circle, and to intentionally support the needs of the practice that are challenging to execute online. This paper focuses specifically on the design and evaluation of the platform rather than the ethnographic study. Specifically, we highlight the following Circle-facilitation tools and methods as both essential to Circle practice and interesting within HCI:

- Circle Seating and Presence. Sitting in a circle together with a center piece is essential within Circle practice, signalling a non-hierarchical, distributed, consensus-based conversation and sharing space where all participants can see one another and be vulnerable together equally. And while Zoom and Google Hangouts allow participants to see one another, perhaps even more directly than they would while in person, the formatting is strictly relegated to a grid, breaking the Circle. 


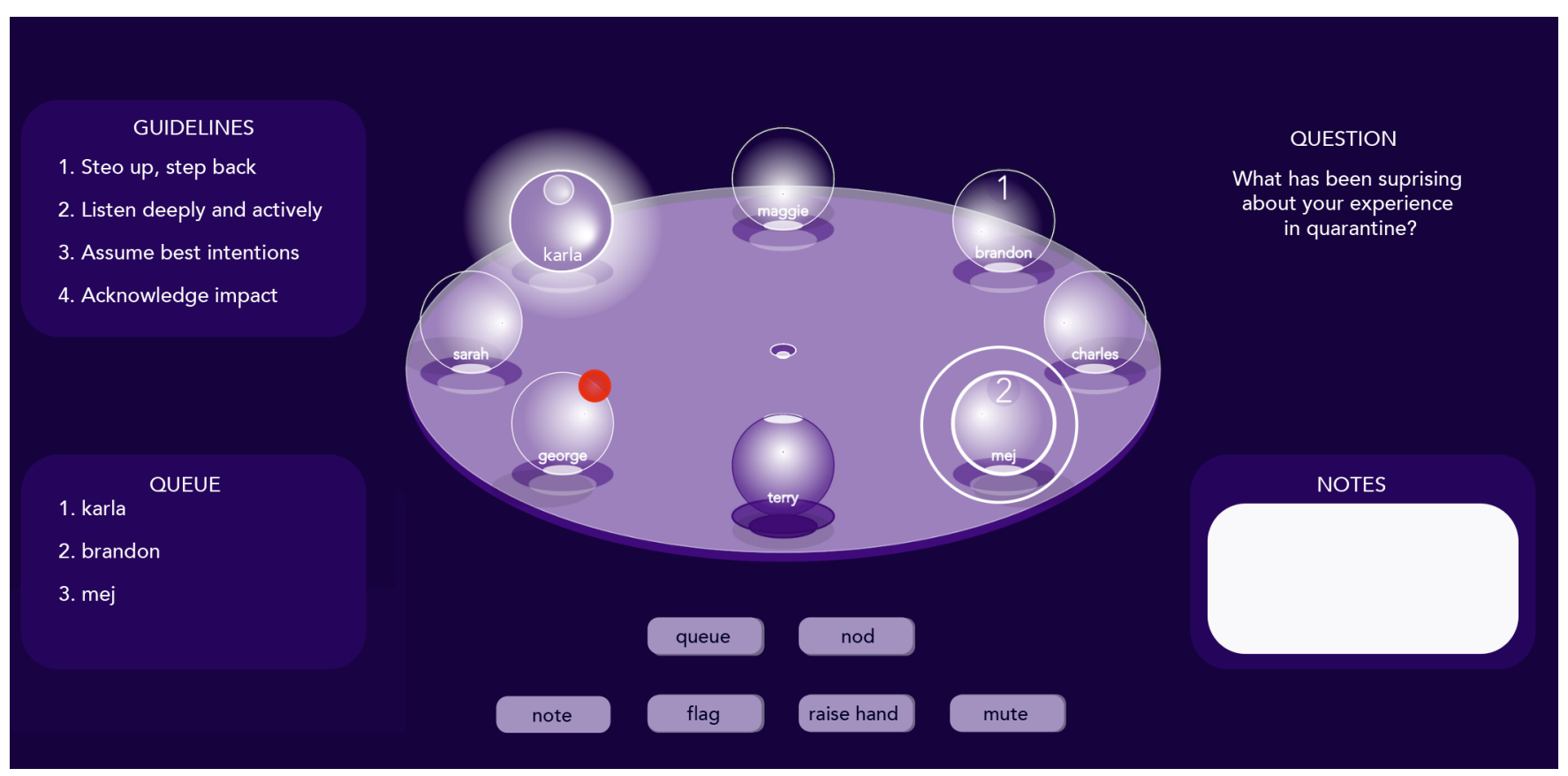

Figure 1: The Keeper Interface. A table at the center holds each user's avatar, a glowing, oscillating orb. The queue for turn taking is on the left and community guidelines are displayed and editable in the top left corner. All interaction buttons are at the bottom middle, and a question is displayed for each circle round at the top right. Private notes can be taken in the bottom left hand corner.

Further, closely aligned with how individuals physically sit, how they connect and experience each other's presence can feel stunted online, inhibiting the power of a Circle, as many Media Richness and Social Presence Theorists have named [34].

- Tone Setting. While a Circle keeper in-person can set the tone of the space through sounds, smells, and light to signal a special, sacred space, online video call environments are not designed for such tone setting. Many facilitators practice tone setting virtually by playing music or through Zoom backdrop choice, but as the online environment is constructed and perhaps more malleable than the physical environment, we believe there was greater opportunity to explore the affordances of tone-setting virtually.

- Talking Piece. As a meaningful object passed around the circle, the talking piece invites whoever has it to have the floor and speak for as long as they would like without interruption before passing the piece. While many HCI tools explore queues and turn taking, few use talking pieces and explore the physical act of passing the piece as is practiced in Circle.

In this paper we present Keeper, an online virtual environment that acts as a compliment to a Zoom or Google Hangout call. While audio is transmitted through the virtual call, participants visually enter the desktop environment in their browser. In this research, we strive to answer the following questions: How does a virtual environment designed informed by Circle practice influence the quality of online facilitated conversations, defining quality as high ease, calm warm, and invited tone, and strong social presence?
Specifically, how might a talking piece, circle seating and a threedimensional space, and aesthetic design influence these domains? In the following section, we outline the key design choices of Keeper to explore these questions, which we hypothesized would improve social presence, ease participation, and promote a calming, welcoming tone in synchronous online calls. We ground those decisions in previous literature in $\mathrm{HCI}$, interface design, and facilitation.

\subsection{Social Presence}

3.1.1 Space. The physical environment a group inhabits is a key feature within Circle and most facilitation practice, so we found it important to explore how we can manipulate the online space to best host Circle. In particular, sitting in an equal circle next to another able to see each person without hierarchy is essential to Circle practice and desirable for most other conversation facilitation styles. Pulling inspiration from others who have challenged traditional structural designs of online gathering spaces [31,37, 46], we designed the space to organize participants around a circle with the perspective changing so each person is at the center of their own screen (Figure 2). With this decision, we prioritized the circle shape and organization over how efficiently the space on the interface is used. We hypothesized that the circle organization would improve the feeling of being physically together in turn improving social presence, as shown in studies exploring VR and depth in relation to social presence and telepresence $[20,33]$. The tilt of the circle into the third dimension and addition of light helps participants experience a depth without sacrificing clarity shown to improve social presence [20]. Further, taking the suggestion of teachers and 
Circle keepers from our initial ethnographic study, we designed features such as passing the talking piece to feel physical in that a user drags the talking piece from the center to themselves or pass it along as one would in an in-person Circle (Figure 3) [15, 47].
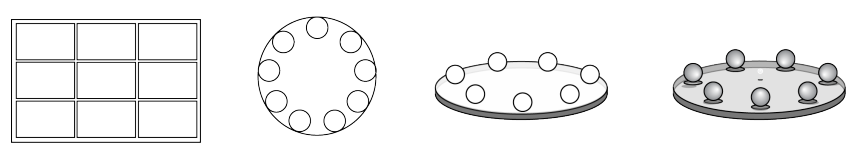

Figure 2: Choice of space within Keeper. From left to right: a video call grid, a $2 \mathrm{D}$ circle, a circle pushed into space, a circle in space with the added dimension of light.
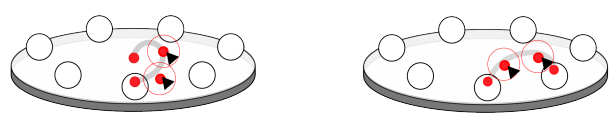

Figure 3: The act of dragging and dropping the talking piece to oneself from the Circle center, or passing to the next person. Talking piece in red for emphasis.

3.1.2 Communication Medium. We chose to use audio only for this platform. Video calls notoriously are interrupted by a participant's living-mates (human or not), odd lighting, the participant's enjoyment of a snack, and the rapid eye movement of reading on a separate browser. While in an experiment setting, one might attempt to enforce strict focus, such restrictions are less realistic in a real-life application. Further, it can feel violating to not have feedback if a person looks at you as one would in person. Video is seen as the richest medium by many Media Richness theorists and offers great depth of communication, yet we wondered what intimacy might open with the release from video, allowing participants to feel sure that no one is staring at them, and pushing them to listen deeply to what others are saying rather than what they look like or what is happening in their background.

We explored using video briefly, but informed by Oh et al. [60]'s study that found evidence of little social presence improvement with the introduction of video and our goal of a relaxed, present, and intimate conversation filled with deep listening, the researchers opted to use audio over audio-video. We prioritize calm tone-setting over the more-rich media of video, hypothesizing that social presence would not be greatly diminished without it.

\section{0}

Figure 4: A single avatar's signal for presence. The first orb on the left signals a dark orb, the participant is not present. Then, the orb oscillates at the rate of a target calm breathing rate.
3.1.3 Avatars and Human Behavior Signals. We decided against humanoid avatars, for they do not necessarily promise high social presence as behavioral signals can [26]. Rather, we sacrificed humanness of avatars for the sake of using the avatars as a means to further design the tone of the space through calming colors, shapes, and animations. However, as avatars with human-behavior signals like nodding improved user's social presence, such signals are included in Keeper in an abstract rendering, including a nodding, harm, and speaking signal (Figure 5), and perhaps the most important, a presence signal (the oscillating glow of an orb shown in Figure 4) [24, 25, 62].

Finally, it is important to note in this exploration, we choose to represent individuals rather than a single visualization of the collective, while other projects explore both representations or representations of the collective $[66,74]$. Circle does emphasize the individual and each person as being invited to speak and bring their own unique perspectives, yet there is also an experience of the collective that we hope to further explore in future iterations.

\subsection{Tone Setting}

Informed by sacred architecture, soma-design, and affective computing design, we chose to develop an environment to elicit calming, inviting, and intimate experiences for a group. Specifically, to prompt depth, calmness, and sacredness, we chose deep blues and purples, often used within art to symbolize sacredness, and socialized within the US and west as a calming, powerful colors. When complemented the pallet with reds, the partnership has been described as harmonious [50]. Further, as sacred architectural spaces emphasize light and contrast, we use strong light contrasts and signals are shared by oscillating lights. Each signal also oscillates at the pace of recommended breathing rates for calmness, seen in Figures 5 and 4 informed by tools like BrightBeat [45]. With this in mind, to allow the avatars to remain abstract but give them a feeling of life, each orb has a light emitting from within it. The table the orbs sit on, as well, feels glowing, as does the talking piece, and the environment has high light contrast. We chose to continue with the circle shape for the abstract avatars, leaning into the cyclical symbolism and calmness of the side-less shape.

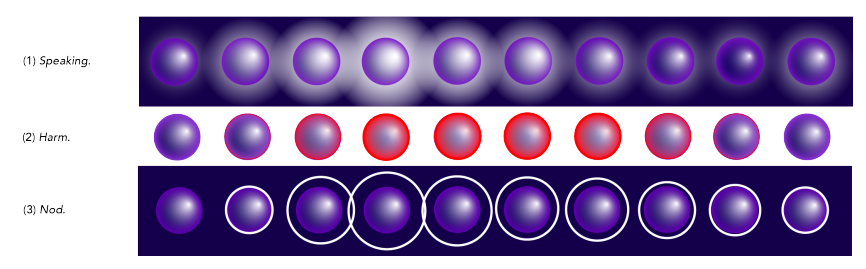

Figure 5: An avatar's signals for speaking and making noise, when they feel harm or negative, and nodding or a more positive signal that might communicate understanding or resonance, as well.

\subsection{Ease and Turn-Taking}

The final component of Keeper we explore in this study is how it eases the flow of conversation with a talking piece (an essential component of Circle practice) and signals such as the queue and 
raise hand features (Figure 6). The talking piece, a small white orb, sits at the center of the circle when not in use. When it sits in someone's avatar, it is their turn to speak. If another user wishes to speak, they can join the queue and have a number in their orb telling the group where that person is in the queue. If an idea or question comes up for the person with the talking piece, a user can "raise their hand" and a small red orb will appear on their avatar. When clicked by the person who's has the talking piece, the small orb will turn white, simulating being "called on." As users finish their turns, users can drag the talking piece to the next person or click "pass talking piece." When finished, the piece sits in the center, and a user can drag it to themselves when ready. Further, the nod feature allows participants to show positive affirmation without audibly interrupting another participant. With these features, Keeper explores turn-taking and how it is eased online with a virtual rendition of physical, simple tools.
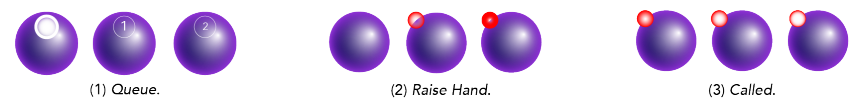

Figure 6: The talking piece in the left-most orb in (1), and a visualization of the queue. (2) Raise Hand as it is up. (3) Raise hand after it has been called on. All signals fade in when clicked and out after clicked again.

\section{METHODS}

This paper hypothesizes that a virtual environment inspired by facilitation practices acting as a container for online, synchronous conversations can improve the quality of those conversations. We define improvement narrowly to mean 1) increased feelings of welcome and calm, 2) increased ease of conversation and flow, and 3) increased social presence. We test this hypothesis through a qualitative study, a randomized control trial, and semi-structured interviews with experienced facilitators.

\subsection{Qualitative Study}

As an attempt to understand the impact of the tool, we conducted the qualitative study with 72 participants. The purpose of this pilot was to identify where the tool failed, evaluate usability, elicit unstructured feedback on specific features, and understand the legibility of the tool. We continued to use an iterative design process to make small adjustments throughout the study period.

The experiment consisted of a conversation hosted by one researcher with at least 3 other participants and a maximum number of 7 participants total across 15 conversations (average of 4 participants, standard deviation $=1.5$ ). Conversations were held at varying times in the day, on weekends and during the week in an effort to accommodate a diverse participant pool. Participants were all students at universities in the area. Each conversation was 45 minutes long, and participants were compensated with a \$15 Amazon gift card.

These conversations were not actively facilitated, and prompts were designed to be ambiguous and spark disagreement. Because it was not an RCT, if the discussion was facilitated it would be difficult to understand if participants' sense of ease, calm, or presence were a factor of the facilitation or Keeper. So we designed slightly tense, ambiguous conversations trying to mitigate the facilitator's presence. Therefore, the facilitator introduced the tool through a scripted introduction to the tool and features, shared the questions, and did no more active facilitating. Questions asked included, "Does social media make us more vain?"; "What advice would you give to children on social media?"; "Should children be taught and evaluated on social and emotional skills like "grit" in school?" and so forth. Questions were chosen for their ambiguity, complexity, and for being common topics that require little outside knowledge. We found that with these questions, an average participant had lived experience to inform their answers, often participants had strong opinions, and such factor's elicited active use of the tool by fostering rapid turn taking, nod signaling, and raise hand signaling.

After 35-40 minutes of this discussion, the remaining time was dedicated to a facilitated focus group reflecting on the group's experience with and reactions to the tool [55]. Questions started broad about the user's general experience, then became more specific about their feelings of calm, awareness of others, and reflection on specific features. Then, an anonymous survey was deployed with similar questions to create multiple mediums for feedback and a space free from researcher bias and social pressures.

Each conversation was audio recorded, and systematic notes were taken throughout observing key patterns and themes that emerged. Specifically, researchers observed how the participants used the talking piece, how they used nodding, raise hand, and harm signals, interruption frequency, and social dynamics such as participants inviting others to speak. After each session, researchers reviewed their notes on the discussion and reviewed the audio recording focusing on the final focus group section. The final 15 minutes were transcribed and coded by theme and valence around specific features (signals, tone setting, turn-taking, design, ease ) and applications of Keeper (if they would use the tool, in what contexts). Snippets of similar themes and valence were clustered together for analysis.

\subsection{Randomized Control Trial}

From the qualitative study, it became clear Keeper potentially eased conversation participation, made participants feel calm and welcome to speak (even when put under pressure and in uncomfortable conversations or passionate), and made them feel warmly towards and aware of one another. To explore the significance of these findings and control for variables such as conversation size, we designed and ran a randomized control trial.

100 participants were recruited from the greater Cambridge area from a pool at the MIT Behavioral Research Center [13]. Participants signed up for a conversation slot, and all slots were dispersed throughout the day and week, including weekends. Each conversation slot was randomly assigned (10) control, (5) partial, and (10) full treatments. A pre-survey designed after the Big 5 Personality test was given to participants to ensure a random distribution of relevant personality traits [38]. Analyzing the distribution, the experiment was successfully randomized, with no close-to significant correlation $(p>0.5)$ between any of the personality traits measured and a treatment. 


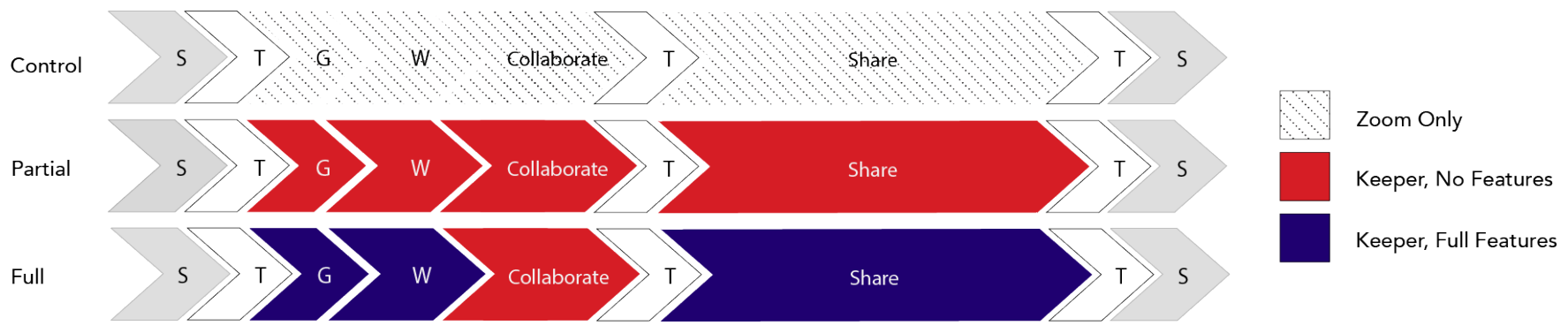

Figure 7: Control, Partial, and Full treatments. $S$ = Pre and Post Surveys completed online 5-point Likert Scale. Pre-survey measured personality and emotion, the post-scale measured experience. $T$ - transition period, allowing 10 minutes for participants to join the video call after the hour. $G$ - General tool instructions. W - Welcome, each person introduces themselves briefly. Collaborate - Collaborative, team-building discussion to break the ice and get to know each other. $T$ - brief transition. Share - 30 minute discussion based on Circle practice.

The study protocol was reviewed and approved by the university IRB. Each participant took a pre-survey as they signed up, and was sent a Zoom link through email with a reminder 30 minutes before their conversation with instructions to keep cameras off. Each conversation consisted of an introduction to the experiment with a brief interactive tutorial of the tool in the full and partial treatments, a welcome with introductions where it was ensured participants did not previously know one another, a collaborative discussion to "warm-up" the conversation, the main Circle discussion, and a closing with a post-survey. The experimenter, trained in Circle, facilitated the discussion and followed a strict script to ensure uniformity across treatments, only offering tool guidance and prompts. In the control, Zoom only condition, cameras were always off. In the partial condition, Keeper was used but only for expressive signals. No talking piece, queue, or raise hand, only tone and some social presence features were used to see if the design of the space itself had impact. The full platform was used in the full condition, except in the collaborate step, for it was used as a warm up that invited rapid turn taking and wasn't designed to use a talking piece.

Each conversation had an average of 5 participants (standard deviation $=1.03$ ) with a minimum of 3 participants present, a maximum of 7. Participants were compensated with a $\$ 15$ card. Prompts were shared verbally by the facilitator, then through text through the Keeper "Question" feature seen in Figure 7 or Zoom chat in the control group. The facilitation script started with a collaborative focus to warm-up where each group was invited to make a list of things each person in the space had in common, what differed between them, and played a desert island survival game, all lasting a max of 15 minutes. Then, the conversation progressed in personal vulnerability and intimacy, first by asking what meaningful object would participants take with them if stranded on an island to keep up their spirit. Participants were asked to tell a story about that object and why it was meaningful to them. After, the prompts evolved into questions about their experiences in quarantine and the 2020 COVID-19 pandemic. This topic was chosen for it's relevance (everyone on the call was being affected in some way and confirmed by a quick yes or no question during each call), emotional connection, and collective impact on the group, all typical characteristics of a Circle conversation. Questions included: "In a word, how would you describe this experience?"; "How have your relationships changed specifically?"; "What has been surprising for you about this experience?"; "Who do you miss seeing the most? Why?"; "What's something new you have learned about yourself in this time?"; "What about you has helped you through this time?" Experiments were recorded and lasted an hour. After each conversation, participants completed a survey.

Each survey question was chosen to measure ease, tone, or social presence. However, upon examining the data collected, we found that while grouping these survey questions by each of these factors had a high Cronbach's alpha (alpha $>0.79$ ), suggesting coherence in the clustering, such factors only accounted for less than $40 \%$ of the variance within our data. Hoping to increase the variance accounted for and to understand more deeply and granularly the data collected, we conducted a second, exploratory factor analysis across the questions to see specifically in each measure where there was improvement, and where there was not. In this exploration using a scree plot, we found 11 factors with Cronbach's alphas for each factor ranged from $83 \%$ to $53 \%$ with over $60 \%$ of variance explained by the factors. Each factor has at least three questions included. This second clustering, however, is merely exploratory and as means to understand our work more granularly. Any significance is reached with greater ease than in the first clustering due to the rise in number of factors, and should not be taken as meaningfully as the first clustering, but simply as an exploration. Results are presented in Figures 8 and 9, and the appendix.

To evaluate these data, the research team used a multiple linear regression controlling for each individual conversation and treatment which normalized for conversation size and individual participation factors. Detailed results from the regression are in the appendix.

\subsection{Facilitator Interviews and Play Tests}

Finally, we conducted semi-structured interviews with 4 Circle facilitators, and 4 facilitators of other methods that either are similar to or derive from Circle practice. Following standard HCI research [55], we chose semi-structured interviews in an attempt to capture the nuance of each expert's knowledge and the complexity of their experience. Each interview consisted of a 10 minute introduction to the tool, followed by a flexible window for the interviewee's 
exploration of the tool and clarifying questions. Interviews were recorded and transcribed. A code was developed to identify themes within each interview, and the code evolved throughout analysis until no new trends emerged and the code was locked. Once that final code had been developed, the first author reviewed the interviews again and applied the final code to all interviews, and began to cluster each coded interview snippet into larger themes. Interview questions were driven by the overall research questions, and included, "How might this tool support your facilitation? In what scenarios might you use it? How would it hinder your facilitation? What is missing? Where might it fall short?"

\section{RESULTS:}

\subsection{Qualitative Study}

In our qualitative study, when asked how participants felt during the conversation the majority of the responses (approx. 2/3) referenced some feelings of calmness, engagement, welcome, invitation, interest, comfort, connection, naturalness, or relaxation. The rest (approx. 1/3) suggested feeling more neutral or negative tones and feelings, such as stilted, awkward, bored, shy, fine, or neutral.

In every conversation at least one person offered their opinions on the ease of participation on Keeper, highlighting that awkwardness and anxiety was relieved: "Once I joined the queue, I didn't feel like I had to wait for social cues or until the other person was finished speaking to interject. The social anxiety from waiting to speak and awkward silences was nearly completely eliminated" suggesting that perhaps, the talking piece was a key factor in tone setting. Participants highlighted general smoothness: "If I had this in any other video call, it would have gone a lot smoother" "Completely got rid of interruptions". Further, as it does in Circle, participants found that the talking piece and the knowledge that their turn will come allowed for more deep listening: "The tool let me listen more actively while not worrying about interrupting someone or having to fight to get my views in".

Participants highlighted that the tool might offer aid to those who are shy as well: "In this way, I think that it allows people who are shy of cutting people off in conversations the chance to speak too." Some suggested surprise at the flow and ease: "Yes - I thought it would be a lot more chaotic, but the conversation flowed really well." In the open-ended questions reflecting on the full-condition experience, participants cited the queue as enabling ease: "I felt like I could participate more easily by joining the queue when I had a thought. Often on conference calls, there is an awkward moment where $2+$ people try to speak at once, and that can give me some anxiety" further suggesting the talking piece contributed to setting the tone of the conversation, as well. And participants generally found the interface to be "simple and intuitive to use".

Many participants further reflected on how the interface made not only their participation easier, but prompted increased selfawareness and reflection as well: "I definitely was able to self regulate better making sure I was an equal speaker and listener" Further, another participant explains "The talking piece helped me feel more aware of my tendency or desire to interrupt, and to curb it!" And another: "The talking piece made me more cognizant of my inconversation habits and prevented me from accidentally interrupting someone else." About 10 participants in the qualitative study felt that their participation was restricted with the turn taking infrastructure, for they could not speak when they wanted to if other's had the talking piece.

In terms of social presence some participants in the qualitative study suggested they were surprised at their feelings of closeness: "From a design perspective the space... In other forms you'd either have an image of the person or not and that should make you feel closer, but just from the setting you created it makes you feel closer. Which I didn't expect it to work that way but it does." Without prompting, over $30 \%$ of participants commented positively on the design of the space in the post-survey, highlighting the calming nature. Only two participants found the design distracting or uncomfortable.

About $10 \%$ of participants used the raise hand feature and about $40 \%$ used the nod feature. In the final focus group when asked, most participants believed the raise hand feature to be useful or liked the thought, but found it hard to use in such a short conversation. Those who used the nod feature appreciated that it took one small click to signal affirmation, as opposed to interrupting or having to speak. A few suggested moving away from the abstract signal to more obvious symbolism such as a thumbs-up or smiley face.

Finally, though never framed in a classroom setting, close to 15 participants drew that link: "Normally I don't like class conversations because I never know when it is my turn to speak or interject. I don't like speaking up when I don't know when people are done talking usually but if I had this... it's nice to have a queue" Another emphasizes the theme, "It is definitely something I haven't seen yet but think we need in today's classrooms," suggesting the potential for tools such as this within the real wold and school settings.

\subsection{Randomized Control Trial}

Within the RCT, tone improved significantly from the control to the full condition ( $p<0.1$, Figure 8 ), and two out of five tone factors showed significant improvement from the control to full treatment in the 11 factor exploratory analysis $(\mathrm{p}<0.05)$. Specifically, feelings of calmness, relaxation, and depth of listening improved (Figure 9 Tone (b)), and a drive to share vulnerably and often (Figure 9 Tone (c)) showed significant improvement. In the exploratory analysis, no patterns of improvement emerged in the following measures: feeling heard by others, invited to speak, welcome, engaged, or focused (Figure 9 Tone (a)), and the tool did not significantly decrease feelings of pressure, anxiety (Figure 9 Tone (d)), or embarrassment and shame (Figure 9 Tone (e)) though all patterns suggested some improvement in tone from control to treatment.

We see in Figure 8, that ease had the most significant improvement from the control to the full treatment $(\mathrm{p}<0.05)$, and had the most significant improvement within the 11 factor analysis as well, though ease only manifested as one factor.

Within the RCT in all conditions, participants reported experiencing high levels of social presence (average Likert response for all conditions $>4$ ). And while with the introduction of Keeper, reports of social presence rose, this increase was the smallest jump compared to all other measures and without significance in the 3 factor analysis. Within the 11 factor exploration, two factors of social presence emerged as significant $(p<0.05)$, suggesting improvement in social presence from the control to the full treatment in the following measures: connection with other participants, feeling 

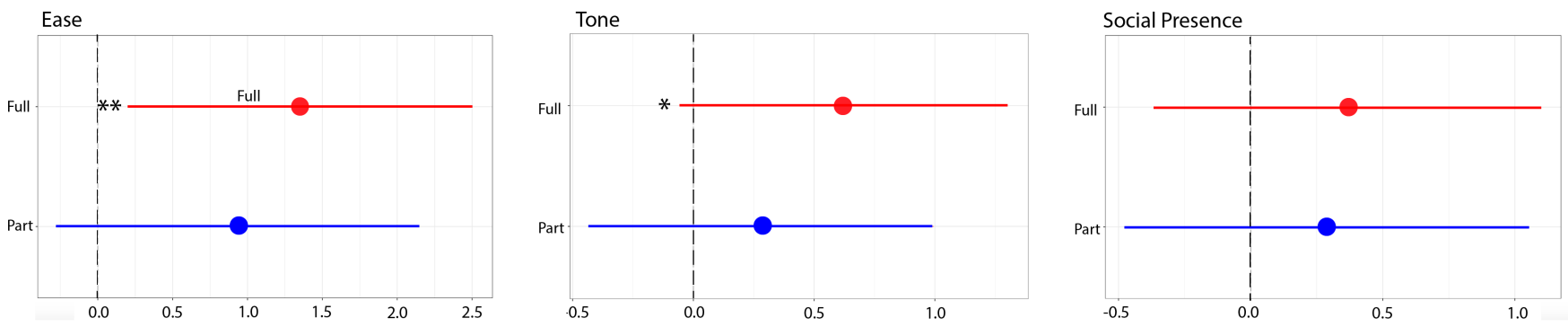

Figure 8: After controlling for conversation, we can see an improvement in average answers for the three measures of interest: Ease, Tone, and Social Presence. Ease and Tone both have significant improvements for the Full treatment, while Social Presence shows no significant improvement. With the introduction of Keeper, Ease estimates to improve by 1.4 points (on a 5 point Likert scale), Tone by 0.6 , and SP by 0.4. Regression table in Appendix A Note: $p<0.1^{*}, p<0.05^{* *}, p<0.01^{* * *}$
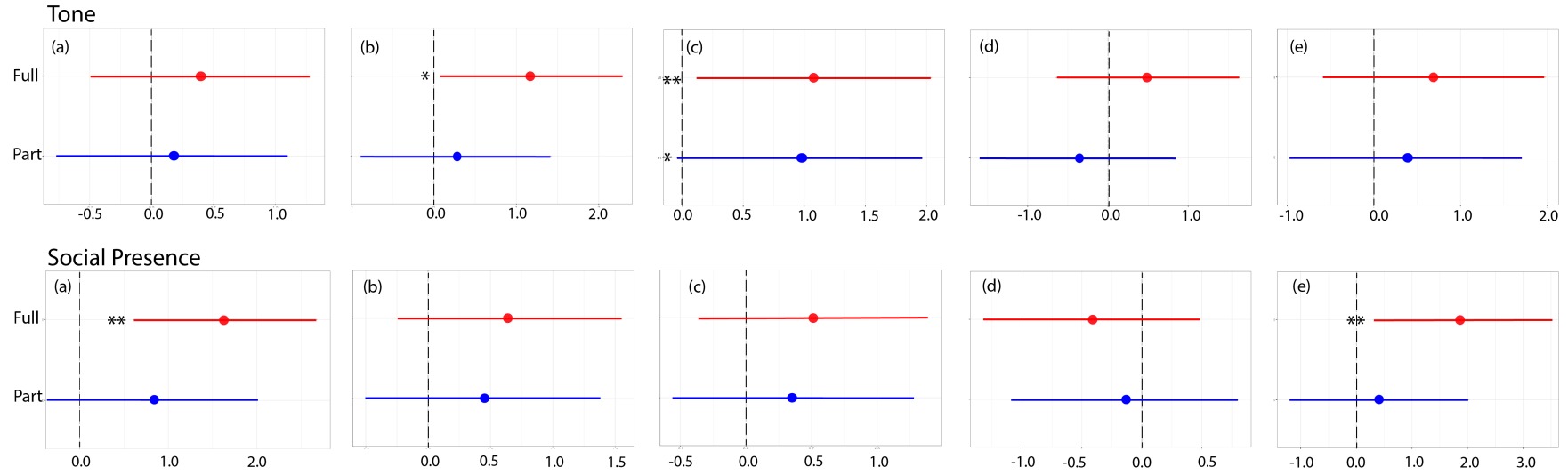

Figure 9: We did an exploratory factor analysis to more granularly analyze the data. Ease only had one factor with similar results, so here we included the 5 factors found for tone and social presence. This is purely exploratory and increases likelihood of finding significance, but should interpreted only as an exploration into what factors specifically improved user experience within tone and social presence. Regression tables in Appendix B Note: $p<0.1^{*}, p<0.05^{* *}, p<0.01^{* * *}$ Tone: A: [feelings of being heard, invitation to speak, welcome], B: [feelings of relaxation, calm, less anxiety]. C: [vulnerability, active listening], D: [pressure to speak, anxiety (reversed survey)], E: [feelings of shame, misunderstanding (reversed survey)] Social Presence: A: [feeling connected, other participant's presence, specialness, closeness, security], B : [feelings of coldness, silence, realness of people (reversed survey)], C: [positive feelings, presence of other participants, empathy towards others], D: [pride for giving other's space to speak, cannot distinguish from video conversations, had participant's in their mind's eye], E: [feelings of closeness]

other participant's presence, closeness with participants (Figure 9 Social Presence (a)), and specialness of the group and conversation (Figure 9 Social Presence (e)). No significant improvement was shown in the following measures in the exploratory factor analysis: feeling less coldly towards others, feeling more empathetic towards others, having other's in one's mind's eye when they speak, and Keeper as indistinguishable from video conversations (Figure 9 Social Presence (d), which actually decreased from control to treatment). Further details can be found in the appendix.

\subsection{Unstructured Expert Interviews}

Within expert interviews, every interviewee thought the talking piece, queue, and raised hands would be deeply valuable for their Circles, some had even already come up with the idea: "I was just talking about these things the other day... talking pieces and sitting in circle, we've literally identified this as a need and this speaks to that need." However, 3 interviewees also emphasized the need of a facilitator to control and break the queue and move the talking piece, if necessary (which is integrated into the tool when participants are granted special facilitator privileges. We do not go into detail here for we do not evaluate these privileges).

Expert facilitators also found the tone of the space inviting, with 6 elaborating on the tone setting taking place in the design: "Love the colors and the visual of the space, it is powerful to come in and see the orbs and the light in the orbs and the way they're moving there is something about it that communicates quite powerfully that this is a conscious space, this is an intentional space. That really takes advantage of or taps into the senses that are beyond the auditory. 
Tone is communicated that way." Further, one expert facilitator expressed fascination at the humanness of the space, explaining "It's so... human" when referencing the orbs, presence and speaking animations, seating, and glows the moment the platform opened.

However, from the expert-facilitator interviews emerged the following critiques in regard to social presence and similar themes on Keeper. First, one facilitator highlight that it was absolutely essential to see everyone's face as a facilitator, especially in challenging conversations, to best react and respond to the complex, nuanced experiences and expressions in the room. Two others had less conviction, but questioned the use of avatars over video. Two others speculated that audio only could invite a more vulnerable, honest, and intimate discussion.

Secondly a related theme emerged around emotional and energetic presence from three facilitators: "The 'aha!' moments come to people through moments of tension. In person, we're all holding [the tension] together, and I can create the energetic space to do that. When it's done, well, everyone was a part of it. Online, it is hard to build a moment of tension that is sustained." One facilitator, explaining a similar phenomena, explained that he felt that "Video can help with that, but feels like it barely helps." This facilitator said he felt as if he was almost blinded online. Two other facilitator pushed this theme as well from a different angle, asking what signals might we craft online that go beyond what we are able to read or signal in-person? This theme of critique less-so critiqued Keeper compared to other forms of $\mathrm{CMC}$, but rather challenged the researchers and designers to push beyond and ask different questions oriented around emotional energy, tension, signals, and presence for future iterations. These interviewees challenged the researchers to think: How might we push and innovate beyond what human capacity in-person might allow with the aid of technology?

\section{DISCUSSION AND FUTURE WORK}

It is clear that there is rich potential in exploring technology and interface design informed by powerful ancient social technologies such as Circle. In this study, we present one example of a platform design and how that design improves online conversation. From this effort, a few themes and learning emerged that might offer aid to those designing systems within this realm in the future.

\subsection{Themes}

CMC and in-person facilitation knowledge. First, a clear gap in exists within $\mathrm{HCI}$ around the goals of virtual facilitation platforms, for almost all commercial platforms found conduct little research on the platform's impact, and when research occurs in the HCI or CSCW community, the platform's quality is evaluated by a group's ability to solve a puzzle, the time required to complete a task, or quality of democratic deliberation [30, 35, 52]. This study is directly informed by the goals of Circle and prioritizes the affect and experience of the user over efficiency. A qualitative study, RCT, and series of expert interviews show the impact of the current tool in significantly improving a participant's feelings of calm and invitation to speak online discussions. Further, we show how this tool can reduce anxiety and ease a user's participation in conversations. We also highlight its short-comings (improving social presence, not exploring video in depth, etc.), and offer a clear direction to explore further with potential to not only improve quality of facilitated online conversation, but expand communication past traditional limits by exploring how we might push and innovate beyond what human capacity in-person might allow with the aid of technology. Such results show that using the wisdom of in-person facilitation practices and other human social technologies to design HCI and interfaces can improve the quality of CMC and push the space towards innovation. We believe this work contributes to HCI and humanist collaborations expanding the humanist reach into the more spiritual, emotional form of facilitation of Circle.

Feature Impact. In our exploration, we found that different facets of Keeper significantly improve the ease, tone, and social presence within online conversations. We hypothesized that the three dimensional design and circle seating would increase social presence as well as the presence oscillating signal. Further, we hypothesized that the breathing rate animations, color, and shapes would improve tone. And while the RCT found little significant improvement for social presence from control to treatment, expert facilitators identified these features as valuable explorations in improving social presence and tone. Further, participants reported feeling great calmness and anxiety relief, more active listening, and more active participation from the talking piece and the queue. The talking piece seemed to be the most exciting and useful feature for most participants, and ease overall showed the most significant improvement in the RCT from control to treatment. However, more exploration is needed to explore the effects of each feature specifically.

Real-World Applications. This platform currently can contribute to the design and implementation of virtual environments that support facilitators and groups as they meet together online. This platform might support those who might not be able to physically connect such as older, ill, or system-involved and incarcerated people, to have intimate experiences in a different way than a video call is able to. Further, many participants drew the link between this platform and children or college students learning. Keeper and work like it has potential contribution for children's social and emotional learning, Restorative Justice and community building in schools, with system involved people, and beyond.

\subsection{Future Work}

Our exploration contributes to previous HCI work that suggests alternative environments to Zoom, Google Hangouts, and other traditional grid-layout video and audio call platforms could improve the quality of facilitated conversations. We acknowledge, however, the vast field that is conversation analysis and group dynamics. All measures in this work are on subjective, self-reported measures offered by each participant, leading to observable patterns, but no objective observations. For future work, we hope to asses more detailed objective measures through conversation analysis of each conversation's transcripts and audio recordings. Further, we hope to explore what other capacities of the virtual domain can be used within online spaces to improve conversation quality, such as metrics, personalized avatars, or reflective visualizations.

For this study, we chose to not use video for its distractions. However, in the future, we hope to more completely explore how video can be augmented (with gaze adjustments, hazing out backgrounds, filters, etc.) to prevent distraction, increase feelings of comfort, and 
enable non-verbal cues and other benefits of video. Finally, expert interviews and participants in the qualitative study lead to a rich discussion filled with potential explorations into how a platform could be designed to not only make online facilitation easier, but perhaps make tension visible, or connection, or engagement, in a way that enhances and expands the capacity of facilitators and Circle beyond that of the in-person experience.

\section{CONCLUSION}

In this paper, we present Keeper, a platform designed informed by the in-person facilitation practice, Circle. We designed Keeper to aid facilitators and groups set the tone of online spaces, ease the flow of conversations, and improve social presence of online conversations through use of color, animations, shapes, and light, through the introduction of scaffolds and signals such as a queue and a nod signal, and through the implementation of a three dimensional, Circle-inspired virtual environment, respectively. Through a qualitative study, a randomized control trial, and 8 expert interviews, we observed patterns that show improved tone setting and ease of conversation with the introduction of Keeper. And while no growth in social presence was reported from the control to Keeper condition, we saw open-ended survey answers, exploratory factor analysis patterns, and feedback from users and experts that suggested the environment also supports improved social presence online. We also received feedback from expert facilitators that suggest the platform did not go far enough, and further exploration and innovation is needed in this space. Implications were given for the application of Keeper in school settings and within virtual Restorative Justice practice. For future work, we hope to contribute to the expansion of projects at the intersection of facilitation-tech, to incorporate objective conversation analysis measures, and to expand the design of the platform incorporating facilitator suggestions.

\section{ACKNOWLEDGMENTS}

The authors acknowledge and thank Belén Saldias for her foundational development work in creating Keeper. The authors thank Essential Partners, Suffolk Center for Restorative Justice, Cortico, MIT's Department of Urban Planning's Colab, Leading Change Network, The Arc of Change, and MIT's U.Lab for their contributions. Specifically, thanks to Dayna Cunningham, Marshall Ganz, Ashley Rose Solomon, Langston Peace, Caitlin Domino, John Sarrouf, Parisa Parsa, Colleen Butler, Anita Krishnan, Abel Cano, Eva Pomeroy, Toni Moya-Latorre, and many more for the wisdom they offered that made this work possible.

\section{REFERENCES}

[1] 2020. Circl.es. https://www.circl.es/

[2] 2020. Depression and Bipolar Support Alliance: Online Support Groups. https://www.dbsalliance.org/support/chapters-and-support-groups/onlinesupport-groups/

[3] 2020. Designing for purpose in virtual engagements. https://whatisessential.org/ resources/designing-purpose-virtual-engagements

[4] 2020. Designing Online Meetings that Feel (Almost) Real. https://medium.com/ agilelab/designing-online-meetings-that-feel-almost-real-b83a8413f2d3

[5] 2020. Howspace. https://www.howspace.com/

[6] 2020. Impact fustice. https://impactjustice.org/

[7] 2020. The Indigenous Origins of Circles and How Non-Natives Learned About Them. http://www.livingjusticepress.org/?SEC=0F6FA816-E094-4B96-8F399922F67306E5
[8] 2020. Let the circle be unbroken: Online restorative circles show social distancing can't stop connection. https://www.lssnd.org/post/let-the-circle-be-unbrokenonline-restorative-circles-show-social-distancing-can-t-stop-connection

[9] 2020. Living Fustice Press. http://www.livingjusticepress.org/

[10] 2020. Local Voices Network. https://www.lvn.org/

11] 2020. Meeting VR Beta. https://www.meetinvr.com/

[12] 2020. Miro. https://www.miro.com/

[13] 2020. MIT Behavioral Research Lab. https://brl.mit.edu/

[14] 2020. Mural. https://www.mural.co/

[15] 2020. The Online Circle Keeper Tool Kit. https://www.suffolk.edu/-/media/suffolk/ documents/cas/centers-institutes/center-for-restorative-justice/circle-keepertoolkit.pdf?la=en\&hash $=451 \mathrm{C} 2 \mathrm{FF} 326 \mathrm{CD} 04 \mathrm{DB} 8424 \mathrm{~A} 6123381 \mathrm{E} 01958270 \mathrm{DA} 8$

[16] 2020. Restorative fustice for Oakland Youth. http://rjoyoakland.org/

[17] 2020. Stormz.me. https://stormz.me/en/features

[18] 2020. Training For Change. https://www.trainingforchange.org/

[19] 2020. Unity Circles. http://unitycircles.org/

[20] Dohyun Ahn, Youngnam Seo, Minkyung Kim, Joung Kwon, Younbo Jung, Jungsun Ahn, and Doohwang Lee. 2014. The Effects of Actual Human Size Display and Stereoscopic Presentation on Users' Sense of Being Together with and of Psychological Immersion in a Virtual Character. Cyberpsychology, behavior and social networking 17 (03 2014). https://doi.org/10.1089/cyber.2013.0455

[21] Neville Alexander. 2002. An ordinary country: Issues in the transition from apartheid to democracy in South Africa. University of Kwazulu Natal Press.

[22] Beard F. K. \& Walther J. B Anderson, J. F. [n.d.]. Turn-taking and the local management of conversation in a highly simultaneous computer-mediated communication system. Language@Internet 7 ([n.d.]).

[23] Roopa B Ankad, Anita Herur, Shailaja Patil, GV Shashikala, and Surekharani Chinagudi. 2011. Effect of short-term pranayama and meditation on cardiovascular functions in healthy individuals. Heart views: the official journal of the Gulf Heart Association 12, 2 (2011), 58.

[24] Jana Appel, Astrid von der Pütten, Nicole C Krämer, and Jonathan Gratch. 2012. Does humanity matter? Analyzing the importance of social cues and perceived agency of a computer system for the emergence of social reactions during humancomputer interaction. Advances in Human-Computer Interaction 2012 (2012).

[25] Gary Bente, Sabine Rüggenberg, Nicole C Krämer, and Felix Eschenburg. 2008. Avatar-mediated networking: Increasing social presence and interpersonal trust in net-based collaborations. Human communication research 34, 2 (2008), 287-318.

[26] Jim Blascovich, Andrew Beall, Kimberly Swinth, Crystal Hoyt, and Jeremy Bailenson. 2002. Immersive Virtual Environment Technology as a Methodological Tool for Social Psychology. Psychol. Inq 13 (08 2002).

[27] Stéphane Bouchard, François Bernier, Éric Boivin, Brian Morin, and Geneviève Robillard. 2012. Using biofeedback while immersed in a stressful videogame increases the effectiveness of stress management skills in soldiers. PloS one 7, 4 (2012), e36169.

[28] Carolyn Boyes-Watson and Kay Pranis. 2015. Circle Forward: Building a Restorative School Community.

[29] Richard P Brown and Patricia L Gerbarg. 2005. Sudarshan Kriya Yogic breathing in the treatment of stress, anxiety, and depression: part II-clinical applications and guidelines. Fournal of Alternative \& Complementary Medicine 11, 4 (2005), 711-717.

[30] Dan Calacci, Oren Lederman, David Shrier, and Pentland. 2016. Breakout: An Open Measurement and Intervention Tool for Distributed Peer Learning Group. In In Proceedings of the 2008 ACM conference on Computer supported cooperative work (CSCW'16).

[31] Robert Cavalier, Miso Kim, and Zachary Sam Zaiss. 2009. Deliberative democracy, online discussion, and project PICOLA (Public informed citizen online assembly). Online deliberation: Design, research, and practice/Eds. Davies T., Gangadharan SP Stanford, CA: Center for the study of language and information (2009), 71

[32] Roberts Coates, Mark Umbreit, and Betty Vos. 2003. Restorative justice circles: An exploratory study. Contemporary fustice Review 6, 3 (2003), 265-278. arXiv:https://doi.org/10.1080/1028258032000115985

[33] James Cummings and Jeremy Bailenson. 2015. How Immersive Is Enough? A Meta-Analysis of the Effect of Immersive Technology on User Presence. Media Psychology 19 (05 2015), 1-38. https://doi.org/10.1080/15213269.2015.1015740

[34] R.H. Daft, R.L.; Lengel. 1986. Organizational information requirements, media richness and structural design. Management Science 32, 5 (1986).

[35] Yngve Dahl and Dag Svanæs. 2020. Facilitating Democracy: Concerns from Participatory Design with Asymmetric Stakeholder Relations in Health Care. In Proceedings of the 2020 CHI Conference on Human Factors in Computing Systems (Honolulu, HI, USA) (CHI '20). Association for Computing Machinery, New York, NY, USA, 1-13. https://doi.org/10.1145/3313831.3376805

[36] Charlie DeTar. 2013. Intertwinkles and digital tools for consensus decisionmaking). Ph.D. Dissertation. Advisor(s) Ethan Zuckerman.

[37] Judith Donath and Fernanda B. Viégas. 2002. The Chat Circles Series: Explorations in Designing Abstract Graphical Communication Interfaces. In Proceedings of the 4th Conference on Designing Interactive Systems: Processes, Practices, Methods, and Techniques (London, England) (DIS '02). Association for Computing Machinery, New York, NY, USA, 359-369. https://doi.org/10.1145/778712.778764 
[38] M. Donnellan, F. Oswald, B. Baird, and R. Lucas. 2006. The Mini-IPIP Scales: Tiny-yet-Effective Measures of the Big Five Factors of Personality. Psychological Assessment 18 (2006), 192-203. https://doi.org/10.1037/1040-3590.18.2.192

[39] Y Earnshaw. 2017. Navigating Turn-Taking and Conversational Repair in an Online Synchronous Course. Online Learning fourna 4, Article 21 (2017).

[40] Arthur Edwards. 2002. The Moderator As an Emerging Democratic Intermediary: The Role of the Moderator in Internet Discussions About Public Issues. Information Polity 7 (04 2002), 3-20. https://doi.org/10.3233/IP-2002-0002

[41] Dmitry Epstein and Gilly Leshed. 2016. The Magic Sauce: Practices of Facilitation in Online Policy Deliberation. Journal of Deliberative Democracy 12 (06 2016), 4 https://doi.org/10.16997/jdd.244

[42] W. Fischer. 2018. Local Voices, Better Journalism. (2018). https://medium.com/ centerforcooperativemedia/local-voices-better-journalism-b3e1faa0a768

[43] Donata Francescato, Rita Porcelli, Minou Mebane, Marcella Cuddetta, Jane Klobas, and Paolo Renzi. 2006. Evaluation of the Efficacy of Collaborative Learning in Face-to-Face and Computer-Supported University Contexts. Comput. Hum. Behav. 22, 2 (March 2006), 163-176. https://doi.org/10.1016/j.chb.2005.03.001

[44] Harold Garfinkel. 1967. What is ethnomethodology. Studies in ethnomethodology (1967).

[45] Asma Ghandeharioun and Rosalind Picard. 2017. BrightBeat: effortlessly influencing breathing for cultivating calmness and focus. In Proceedings of the 2017 CHI Conference Extended Abstracts on Human Factors in Computing Systems. 1624-1631.

[46] Drew Harry and Judith Donath. 2008. Information Spaces - Building Meeting Rooms in Virtual Environments. In CHI '08 Extended Abstracts on Human Factors in Computing Systems (Florence, Italy) (CHI EA '08). Association for Computing Machinery, New York, NY, USA, 3741-3746. https://doi.org/10.1145/1358628. 1358923

[47] Maggie Hughes. 2020. Keeper: Online conversation support scaffolding modeled after ancient and modern social technologies. Master's thesis. Advisor(s) Deb Roy.

[48] Kristina Höök, Anna Ståhl, Martin Jonsson, Johanna Mercurio, Anna Karlsson, and Eva-Carin Johnsson. 2015. Somaesthetic Design. interactions 22 (07 2015). https://doi.org/10.1145/2770888

[49] Harri Kaloudis. 2020. A very brief introduction to sociocracy. https://medium. com/@Harri_Kaloudis/a-brief-introduction-to-sociocracy-a0770f220937

[50] W. Kandinsky. 1977. Concerning the Spiritual in Art. Dover Publications. https: //books.google.com/books?id=mG-VRWgfpuYC

[51] Hongki Kim, Kil-Soo Suh, and Un-Kon Lee. 2013. Effects of collaborative online shopping on shopping experience through social and relational perspectives. Information \& Management 50, 4 (2013), 169-180.

[52] Hinds P. Pentland A. Kim, T. 2012. Awareness as an antidote to distance: making distributed groups cooperative and consistent. In In Proceedings of the $2012 \mathrm{ACM}$ conference on Computer supported cooperative work (CSCW'08).

[53] A. Lantz. 201. Meetings in a distributed group of experts: comparing face-to-face, chat and collaborative virtual environments. Behav. Inform. Technol. 2, Article 20 (201).

[54] B. Lau. 2008. The poetics of sacred light - a comparative study of the luminous environment in the Ronchamp Chapel and the church in the Monastery of La Tourette. (2008).

[55] Jonathan Lazar, Jinjuan Heidi Feng, and Harry Hochheiser. 2017. Research methods in human-computer interaction. Morgan Kaufmann.

[56] Jill T; Hillis Autumn L. Lund, Maggie K; Green. 2019. The Impact of Restorative fustice Practices on Student Achievement, Attendance, and Discipline in a Middle School Setting. Ph.D. Dissertation. Advisor(s) Ethan Zuckerman.

[57] Monika Mourya, Aarti Sood Mahajan, Narinder Pal Singh, and Ajay K Jain 2009. Effect of slow-and fast-breathing exercises on autonomic functions in patients with essential hypertension. The journal of alternative and complementary medicine 15, 7 (2009), 711-717.

[58] Matti Nelimarkka. 2019. A Review of Research on Participation in Democratic Decision-Making Presented at SIGCHI Conferences. Toward an Improved Trading Zone Between Political Science and HCI. Proc. ACM Hum.-Comput. Interact. 3 , CSCW, Article 139 (Nov. 2019), 29 pages. https://doi.org/10.1145/3359241

[59] Matti Nelimarkka, Jean Philippe Rancy, Jennifer Grygiel, and Bryan Semaan 2019. (Re)Design to Mitigate Political Polarization: Reflecting Habermas' Ideal Communication Space in the United States of America and Finland. Proc. ACM Hum.-Comput. Interact. 3, CSCW, Article 141 (Nov. 2019), 25 pages. https://doi. org $/ 10.1145 / 3359243$

[60] Catherine S. Oh, Jeremy N. Bailenson, and Gregory F. Welch. 2018. A Systematic Review of Social Presence: Definition, Antecedents, and Implications. Frontiers in Robotics and AI 5 (2018), 114. https://doi.org/10.3389/frobt.2018.00114
[61] Olson G.M. Meader D.K. Olson, J.S. [n.d.]. What Mix of Video and Audio is Useful for Small Groups Doing Remote Real-Time Design Work?

[62] Xueni Pan, Marco Gillies, and Mel Slater. 2008. The impact of avatar blushing on the duration of interaction between a real and virtual person. In Presence 2008: The 11th Annual International Workshop on Presence. 100-106.

[63] Taiwoo Park, Uichin Lee, Bupjae Lee, Haechan Lee, Sanghun Son, Seokyoung Song, and Junehwa Song. 2013. ExerSync: Facilitating Interpersonal Synchrony in Social Exergames. In Proceedings of the 2013 Conference on Computer Supported Cooperative Work (San Antonio, Texas, USA) (CSCW'13). Association for Computing Machinery, New York, NY, USA, 409-422. https://doi.org/10.1145/ 2441776.2441823

[64] P. Parker. 2018. The Art of Gathering: How We Meet and Why It Matters. Penguin LCC US. https://books.google.com/books?id=mo86swEACAAJ

[65] Pierre Philippot, Gaëtane Chapelle, and Sylvie Blairy. 2002. Respiratory feedback in the generation of emotion. Cognition and Emotion 16, 5 (2002), 605-627. https://doi.org/10.1080/02699930143000392 arXiv:https://doi.org/10.1080/02699930143000392

[66] C. Y. Qin, M. Constantinides, L. M. Aiello, and D. Quercia. 2020. HeartBees: Visualizing Crowd Affects. In 2020 IEEE VIS Arts Program (VISAP). 1-8. https: //doi.org/10.1109/VISAP51628.2020.00007

[67] Roy A. Rodenstein and Judith S. Donath. 2000. Talking in Circles: A SpatiallyGrounded Social Environment. In Proceedings of the 2000 ACM Conference on Computer Supported Cooperative Work (Philadelphia, Pennsylvania, USA) (CSCW '00). Association for Computing Machinery, New York, NY, USA, 349. https: //doi.org/10.1145/358916.361977

[68] William Bradshaw \& David Roseborough. 2005. Restorative Justice Dialogue: The Impact of Mediation and Conferencing on Juvenile Recidivism. Federal Probation 69, 2 (2005). https://heinonline.org/HOL/Page?handle=hein. journals/fedpro69\&div $=21 \& g$ _sent $=1 \&$ casa_token $=4$ zM4m6WzSxIAAAAA: Oj1LG0-c7jR24LTARuHFOsPwutIZNS9DInMpMFXk9xUsBwz-3fV4F $\mathrm{xC2I1BVeir5nxg \& collection=journals \#}$

[69] Emanuel A. Schegloff Sacks, Harvey and Gail Jefferson. 1974. A Simplest Systematics for the Organization of Turn-Taking for Conversation. Print. Language 4, Article 50 (1974). https://doi.org/10.1145/1057270.1057278

[70] Gustanski J. Sanders, M. and M. Lawton. 1974. Effect of ambient illumination on noise level of groups. (1974)

[71] T. Schielke. 2013. Light Matters: Louis Kahn and the Power of Shadow. (2013). < http://www.archdaily.com/362554/light-matterslouis-kahn-and-thepower-of-shadow/>

[72] Sunaina Soni, Lata N Joshi, and Anjum Datta. 2015. Effect of controlled deep breathing on psychomotor and higher mental functions in normal individuals. Indian f Physiol Pharmacol 59, 1 (2015), 41-47.

[73] Maya Soriano. 2020. Witnessing the Unlimited Potential of Children Being Peaceful: Impact of Proactive Restorative Circle Practice on Early Childhood Students in a Montessori Setting. (2020). https://sophia.stkate.edu/maed/356/

[74] H. Stuart, Laura Dabbish, Sara Kiesler, Peter Kinnaird, and Ruogu Kang. 2012. Social transparency in networked information exchange: A theoretical framework. Proceedings of the ACM Conference on Computer Supported Cooperative Work, CSCW, 451-460. https://doi.org/10.1145/2145204.2145275

[75] Myers J. \& Dennen V. Suggs, C. 2010. Raise Your Hand If You Wanna Speak: Navigating Turn-taking in a Webex Course. In Proceedings of E-Learn 2010World Conference on E-Learning in Corporate, Government, Healthcare, and Higher Education (pp. 2212-2219)). Association for the Advancement of Computing in Education, Orlando, Florida, 7.

[76] Lindsey Holland Taemie Kim, Agnes Chang and Alex Sandy Pentland. 2008. Meeting mediator: enhancing group collaboration using sociometric feedback. In In Proceedings of the 2008 ACM conference on Computer supported cooperative work (CSCW '08). AMC, New York, NY. https://doi.org/10.1145/1460563.1460636

[77] W. Ben Towne and James D. Herbsleb. 2012. Design Considerations for Online Deliberation Systems. Fournal of Information Technology \& Politics 9, 1 (2012), 97-115. https://doi.org/10.1080/19331681.2011.637711 arXiv:https://doi.org/10.1080/19331681.2011.637711

[78] Vos B. Umbreit, M.S. and R.B. Coates. 2006. RESTORATIVE JUSTICE DIALOGUE: Evidence-Based Practice. Center for Restorative fustice \& Peacemaking (2006). http://www.antoniocasella.eu/restorative/Umbreit_2006.pdf

[79] Joseph B. Walther. 1996. Computer-Mediated Communication: Impersonal, Interpersonal, and Hyperpersonal Interaction. Communication Research 23, 1 (1996), 3-43. https://doi.org/10.1177/009365096023001001

[80] Maisha T. Winn. 2018. Fustice on Both Sides: Transforming Education Through Restorative Fustice (Race and Education). Harvard Education Press, Cambridge. 


\section{A REGRESSION TABLES}

Regression table for our initial analysis measuring the change in Social Presence, Tone, and Ease across treatments. Found significant improvement in Tone and Ease from control to Full treatment.
Table 1: Regression Results

\begin{tabular}{lccc}
\hline \hline & \multicolumn{3}{c}{ Dependent variable: } \\
\cline { 2 - 4 } & Social Presence & Tone & Ease \\
& $(1)$ & $(2)$ & $(3)$ \\
\hline Full Treatment & 0.371 & $0.622^{*}$ & $1.350^{* *}$ \\
& $(0.370)$ & $(0.346)$ & $(0.586)$ \\
Partial Treatment & 0.286 & 0.285 & 0.937 \\
& $(0.387)$ & $(0.362)$ & $(0.613)$ \\
\hline Observations & 101 & 101 & 101 \\
$\mathrm{R}^{2}$ & 0.294 & 0.371 & 0.360 \\
Adjusted $\mathrm{R}^{2}$ & 0.083 & 0.182 & 0.169 \\
\hline \hline Note: & & ${ }^{*} \mathrm{p}<0.1 ;{ }^{* *} \mathrm{p}<0.05 ;{ }^{* * *} \mathrm{p}<0.01$
\end{tabular}


Table 2: Tone Granular Regression

\begin{tabular}{lccccc}
\hline \hline & \multicolumn{5}{c}{ Dependent variable: } \\
\cline { 2 - 6 } & Heard, invited & Calm, relaxed & Open, listening & Pressure, anxiety & Shame, misunderstood \\
& $(1)$ & $(2)$ & $(3)$ & $(4)$ & $(5)$ \\
\hline Full Treatment & 0.400 & $1.167^{* *}$ & $1.083^{* *}$ & 0.489 & 0.489 \\
& $(0.457)$ & $(0.555)$ & $(0.490)$ & $(0.583)$ & $(0.583)$ \\
Partial Treatment & 0.167 & 0.292 & $0.958^{*}$ & -0.361 & -0.361 \\
& $(0.478)$ & $(0.581)$ & $(0.513)$ & $(0.610)$ & $(0.610)$ \\
\hline Observations & 101 & 101 & 101 & 101 & 101 \\
$\mathrm{R}^{2}$ & 0.310 & 0.337 & 0.289 & 0.319 & 0.319 \\
Adjusted $\mathrm{R}^{2}$ & 0.103 & 0.139 & 0.077 & 0.115 & 0.115 \\
\hline \hline Note: & & & & $* \mathrm{p}<0.1 ;{ }^{* *} \mathrm{p}<0.05 ;{ }^{* * *} \mathrm{p}<0.01$
\end{tabular}

Table 3: Social Presence Granular Regression

\begin{tabular}{|c|c|c|c|c|c|}
\hline & \multicolumn{5}{|c|}{ Dependent variable: } \\
\hline & $\begin{array}{c}\text { Connected, special, presence } \\
(1)\end{array}$ & $\begin{array}{c}\text { Silencd, cold } \\
(2) \\
\end{array}$ & $\begin{array}{c}\text { Positive, empathetic } \\
\text { (3) }\end{array}$ & $\begin{array}{l}\text { Proud, in mind's eye } \\
\text { (4) }\end{array}$ & $\begin{array}{c}\text { Closeness } \\
(5)\end{array}$ \\
\hline Full Treatment & $\begin{array}{c}1.640^{* * *} \\
(0.533)\end{array}$ & $\begin{array}{c}0.650 \\
(0.458)\end{array}$ & $\begin{array}{c}0.511 \\
(0.448)\end{array}$ & $\begin{array}{l}-0.422 \\
(0.461)\end{array}$ & $\begin{array}{l}1.867^{* *} \\
(0.786)\end{array}$ \\
\hline Partial Treatment & $\begin{array}{c}0.850 \\
(0.557) \\
\end{array}$ & $\begin{array}{c}0.437 \\
(0.479) \\
\end{array}$ & $\begin{array}{c}0.361 \\
(0.469) \\
\end{array}$ & $\begin{array}{l}-0.139 \\
(0.482) \\
\end{array}$ & $\begin{array}{c}0.417 \\
(0.822) \\
\end{array}$ \\
\hline Observations & 101 & 101 & 101 & 101 & 101 \\
\hline $\mathrm{R}^{2}$ & 0.284 & 0.196 & 0.252 & 0.311 & 0.205 \\
\hline Adjusted $\mathrm{R}^{2}$ & 0.071 & -0.045 & 0.028 & 0.105 & -0.033 \\
\hline
\end{tabular}

\section{B EXPLORATORY REGRESSION TABLES}

The following tables are results from our exploratory factor analysis which found 5 unique factors within Tone and Social Presence survey questions. We see these as exploratory and a method to help us understand what factors Keeper actually supported and improved within our measures for Tone and Social Presence. Ease showed the same results. 